University of Nebraska - Lincoln

DigitalCommons@University of Nebraska - Lincoln

Faculty Papers and Publications in Animal

Science

Animal Science Department

July 2002

\title{
Effect of duration of performance test on variance component estimates for lamb growth rate
}

\section{G. D. Snowder}

USDA, ARS, U.S. Sheep Experiment Station, Dubois, ID

L. Dale Van Vleck

University of Nebraska-Lincoln, dvan-vleck1@unl.edu

Follow this and additional works at: https://digitalcommons.unl.edu/animalscifacpub

Part of the Animal Sciences Commons

Snowder, G. D. and Van Vleck, L. Dale, "Effect of duration of performance test on variance component estimates for lamb growth rate" (2002). Faculty Papers and Publications in Animal Science. 229.

https://digitalcommons.unl.edu/animalscifacpub/229

This Article is brought to you for free and open access by the Animal Science Department at DigitalCommons@University of Nebraska - Lincoln. It has been accepted for inclusion in Faculty Papers and Publications in Animal Science by an authorized administrator of DigitalCommons@University of Nebraska - Lincoln. 


\title{
Effect of duration of performance test on variance component estimates for lamb growth rate
}

\author{
G. D. Snowder*1 and L. D. Van Vleck $\dagger$ \\ *USDA, ARS, U.S. Sheep Experiment Station, Dubois, ID 83423 and †USDA, ARS, \\ U.S. Meat Animal Research Center, Lincoln, NE 68583
}

\begin{abstract}
The objective was to determine the effect of periods of adjustment and duration of performance test on estimating genetic variance parameters for ADG. Variance components were estimated from ADG data collected from 1978 to 1984 on a total of 1,047 Targhee ewe and ram lambs at the U.S. Sheep Experiment Station (Dubois, ID). Across all years, lambs averaged $84 \pm 9 \mathrm{~d}$ of age and $25 \pm 5.4 \mathrm{~kg}$ of weight when placed on test. Lambs were provided ad libitum access to a commercial pellet of barley grain and ground alfalfa for 14 wk. Every 2 wk, ADG was recorded. Overall mean ADG for the entire 14-wk period across all years was $249.3 \pm 56.5 \mathrm{~g}$. Variance components were estimated from a single-trait animal model using REML for cumulative combinations of time on feed in 2 -wk intervals from 4 to $14 \mathrm{wk}$ and varying the adjustment period from 2 to $6 \mathrm{wk}$. The model included fixed effects for year (1978 to 1984), sex of lamb (ewe or ram), and genetic line (selected or control), and two covariates (age and weight at beginning of performance test). As
\end{abstract}

the duration of the performance test increased, phenotypic variances for ADG decreased: 54 and $13 \mathrm{~g}^{2}$ at 4 and $14 \mathrm{wk}$ on test, respectively. Also, estimates of direct heritability increased with extended duration on test: $0.20 \pm 0.06$ and $0.35 \pm 0.07$ at 4 and 14 wk on test, respectively. Heritability estimates increased little after 8 wk on feed $(0.33,0.33,0.38$, and 0.35 for $8,10,12$, and $14 \mathrm{wk}$, respectively). Genetic and environmental correlations among durations of the performance test were estimated from two-trait models. All genetic correlations among durations of performance test were greater than 0.88 which suggests that all measures of ADG were genetically similar. However, environmental correlations among duration of performance test ranged from 0.31 to 1.00 with the smaller environmental correlations occurring between 4 to $6 \mathrm{wk}$ with 12 to $14 \mathrm{wk}$ on feed. These results indicate that a period of $8 \mathrm{wk}$ or greater was sufficient to observe differences among animals for ADG due to direct genetic effects under this environment.

Key Words: Growth, Heritability, Selection, Sheep

(C2002 American Society of Animal Science. All rights reserved.

J. Anim. Sci. 2002. 80:2078-2084

\section{Introduction}

Rate of gain is a trait of significant economic importance to the American sheep industry. Selection for increased ADG can result in significant response. Shelton (1979) reported an 80\% improvement in ADG over a 28-yr selection period for centrally tested Rambouillet rams. Even short-term selection can favorably alter biological influences on growth by increasing plasma growth hormone and thyrotropin levels in selected rams (Dodson et al., 1983).

Most ram performance tests evaluate ADG either as a single trait or include ADG within a selection index

\footnotetext{
${ }^{1}$ Correspondence and current address: U.S. MARC, P.O. Box 166, Clay Center, NE 68901 (phone: 402-762-4167; fax: 402-762-4173). snowder@email.marc.usda.gov).

Received July 5, 2001.

Accepted April 19, 2002.
}

to rank individuals. The optimal duration of the feeding period for a performance test to rank breeding animals has been questioned (Knapp et al., 1942; Swiger et al., 1961). If the duration of a performance test for $\mathrm{ADG}$ is too short, animals may not be properly ranked for genetic merit resulting in a very low relationship between a sire's performance and his progeny's performance (Waldron et al., 1990). If a performance test duration is longer than reliably needed, then feed, facilities, and management costs are increased. The objective of this study was to evaluate the effect of duration on test for estimating genetic variation among individuals. The optimal duration(s) should be determined by the estimates of the heritability for gain (Koch et al., 1982), consideration of costs, and the predictive value for the selection objective.

\section{Materials and Methods}

From 1969 to 1984, the U.S. Sheep Experiment Station selected for post-weaning ADG in Targhee sheep. 
For comparison, a random-mated control line was maintained with no selection imposed. Flock size for each line was approximately 130 breeding ewes per year. Each year, four yearling rams were selected for postweaning ADG and mated to ewes in the selected line. In the control line, ewes were randomly exposed to one of 12 randomly chosen yearling rams.

Each year, approximately 150 lambs were individually performance tested for ADG and feed efficiency based on a 14-wk performance test period. All available lambs from the selected line were performance tested (approximately 115 per year). A smaller sample of lambs from the control line (approximately 35 per year) was randomly selected shortly after birth to be performance tested. Across all years, lambs averaged $84 \pm 9$ $\mathrm{d}$ of age and $25 \pm 5.4 \mathrm{~kg}$ of weight when placed on test. Lambs were vaccinated for Clostridium perfringens types $\mathrm{C}$ and $\mathrm{D}$ prior to the feeding period with a second vaccination 2 wk later. Lambs were divided into two groups by sex (ram or ewe) and fed in open lots with partial shade for $10 \mathrm{wk}$. The first 2 -wk period was considered to be an adjustment period with the data not analyzed. Following the 10 -wk group feeding period, lambs were individually fed for $6 \mathrm{wk}$ to measure individual feed efficiency. Individual pens were $1.25 \times 2.45 \mathrm{~m}$, and partial shade was provided for each lamb. Body weights were measured for analysis every 2 wk beginning at the end of the adjustment period. Feed intake was measured only during the individual feeding period.

Lambs were given free access to commercial pellets comprised of $37 \%$ barley grain and $63 \%$ alfalfa with an estimated dietary energy of $3.20 \mathrm{Mcal} / \mathrm{kg}$. Although intakes varied among lambs, average intakes over the 14-wk period were sufficient to meet NRC energy requirements for maintenance and growth (NRC, 1985). Fresh water and a commercial salt and mineral mix were freely available. Lasalocid (Roche Vitamins, Inc., Parsippany, NJ) was added to the salt and mineral mix to prevent and control coccidial disease. Lambs were checked twice daily for health and proper feeding conditions. To reduce effects of feeding pen during the individual feeding period, lambs were rotated every $2 \mathrm{wk}$ among the feeding pens.

The data were limited to the years 1978 to 1984 because data in previous years were unreliable due to inconsistent record keeping and severe environmental conditions affecting lamb performance (i.e., extended periods of heavy rains). A summary of the data for years 1978 to 1984 is reported in Table 1.

Because the objective was to determine whether duration on test influences the estimates of genetic parameters, various combinations of feeding intervals were examined. First, various lengths of adjustment periods ranging from 2 to 6 wk were considered because the adjustment period to a feeding regimen may influence performance on test. Second, the duration of the performance test period was examined by extending the usual 2 -wk intervals from 4 to $14 \mathrm{wk}$. The adjustment period always starts at wk 0 , and the test period always follows the adjustment period. Only cumulative 2 -wk periods were examined (not all possible combinations of feeding periods) for a total of 15 combinations of adjustment and duration periods (Table 2). Durations of test were numerically coded to indicate periods of adjustment and performance test (e.g., $2 \cdot 4$ indicates a 2 -wk adjustment period followed by a 4 -wk performance test period). Average daily gain was calculated as the mean of the ADG values from each 2 -wk period during the performance test.

The data comprised 8,834 records for a total of 1,047 Targhee ewe and ram lambs from 88 sires. Individual values for $\mathrm{ADG}$ more than three standard deviations from the overall mean within each duration period were considered as outliers and discarded. This edit resulted in a removal of less than $3 \%$ of the data and was not associated with any particular adjustment or performance-test duration period.

Genetic analyses required identification of the genetic relationships among the lambs. The relationship matrix generated from the Targhee pedigree file included animals born from 1950 to 1984 , a total of 27,982 animals. The average inbreeding coefficient of inbred lambs was small (1.9\%); therefore, the effects of inbreeding on ADG were assumed to be negligible.

Variance and covariance components for ADG were estimated using single- and two-trait models using a derivative-free REML algorithm (Graser et al., 1987) with the computer programs of Boldman et al. (1995). Convergence was considered to have been reached when the variance of the $-2 \log$ likelihood in the simplex was less than $1 \times 10^{-6}$. After initial convergence, four restarts were performed to ensure global convergence as determined when the $-2 \log$ likelihood did not change to the second decimal.

Single-trait analyses were performed for each duration of performance test. The model included as fixed effects: year of performance test (1978 to 1984), genetic selection line (control and selected), and sex (ram and ewe). Age and weight at the end of the adjustment period were included as linear covariates. The additive genetic effect of the lambs and residual effect were considered as random effects. The standard errors of the heritability estimates were based on the average information matrix and the "delta" method (Dodenhoff et al., 1998). Favorable combinations of adjustment period and of performance test were identified as the greater proportion of the phenotypic variance being accounted for by the additive genetic variation, thus, having the highest heritability estimates when compared together (Koch et al., 1982).

Because the lambs were fed in a group for $8 \mathrm{wk}$ and then as individuals for $6 \mathrm{wk}$, the effect of feeding management (group, individual) was investigated in preliminary analyses of overall ADG. This effect was not significant $(P=0.37)$. Therefore, feeding management was not included as a fixed effect in the model. 
Table 1. Number of lambs, mean (SD) age (days) at start of test, initial and final weights $(\mathrm{kg})$ by year, sex, and genetic line

\begin{tabular}{|c|c|c|c|c|c|}
\hline Year and sex & Line & Number & Age & Initial wt. & Final wt \\
\hline \multicolumn{6}{|l|}{1978} \\
\hline \multirow[t]{2}{*}{ Male } & Control & 16 & $93 \pm 5$ & $30 \pm 4$ & $57 \pm 6$ \\
\hline & Select & 53 & $90 \pm 3$ & $31 \pm 5$ & $60 \pm 8$ \\
\hline \multirow[t]{2}{*}{ Female } & Control & 14 & $93 \pm 6$ & $27 \pm 4$ & $43 \pm 5$ \\
\hline & Select & 61 & $91 \pm 6$ & $30 \pm 4$ & $50 \pm 6$ \\
\hline \multicolumn{6}{|l|}{1979} \\
\hline \multirow[t]{2}{*}{ Male } & Control & 17 & $95 \pm 3$ & $27 \pm 4$ & $51 \pm 4$ \\
\hline & Select & 61 & $90 \pm 5$ & $27 \pm 5$ & $55 \pm 7$ \\
\hline \multirow[t]{2}{*}{ Female } & Control & 14 & $95 \pm 4$ & $26 \pm 4$ & $45 \pm 6$ \\
\hline & Select & 55 & $89 \pm 5$ & $27 \pm 4$ & $48 \pm 6$ \\
\hline \multicolumn{6}{|l|}{1980} \\
\hline \multirow[t]{2}{*}{ Male } & Control & 13 & $94 \pm 3$ & $28 \pm 5$ & $57 \pm 13$ \\
\hline & Select & 68 & $90 \pm 6$ & $29 \pm 6$ & $65 \pm 8$ \\
\hline \multirow[t]{2}{*}{ Female } & Control & 18 & $95 \pm 4$ & $26 \pm 5$ & $51 \pm 6$ \\
\hline & Select & 59 & $90 \pm 6$ & $26 \pm 6$ & $54 \pm 7$ \\
\hline \multicolumn{6}{|l|}{1981} \\
\hline \multirow[t]{2}{*}{ Male } & Control & 14 & $91 \pm 3$ & $26 \pm 4$ & $53 \pm 6$ \\
\hline & Select & 45 & $87 \pm 5$ & $28 \pm 6$ & $60 \pm 7$ \\
\hline \multirow[t]{2}{*}{ Female } & Control & 14 & $91 \pm 3$ & $24 \pm 5$ & $45 \pm 4$ \\
\hline & Select & 67 & $87 \pm 5$ & $26 \pm 4$ & $52 \pm 5$ \\
\hline \multicolumn{6}{|l|}{1982} \\
\hline \multirow[t]{2}{*}{ Male } & Control & 15 & $81 \pm 4$ & $25 \pm 5$ & $59 \pm 6$ \\
\hline & Select & 37 & $79 \pm 7$ & $25 \pm 5$ & $62 \pm 7$ \\
\hline \multirow[t]{2}{*}{ Female } & Control & 19 & $79 \pm 5$ & $21 \pm 5$ & $47 \pm 8$ \\
\hline & Select & 55 & $78 \pm 6$ & $22 \pm 5$ & $52 \pm 7$ \\
\hline \multicolumn{6}{|l|}{1983} \\
\hline \multirow[t]{2}{*}{ Male } & Control & 18 & $82 \pm 5$ & $26 \pm 7$ & $56 \pm 10$ \\
\hline & Select & 57 & $77 \pm 6$ & $26 \pm 5$ & $58 \pm 6$ \\
\hline \multirow[t]{2}{*}{ Female } & Control & 21 & $83 \pm 5$ & $22 \pm 5$ & $44 \pm 6$ \\
\hline & Select & 66 & $78 \pm 5$ & $22 \pm 4$ & $50 \pm 5$ \\
\hline \multicolumn{6}{|l|}{1984} \\
\hline \multirow[t]{2}{*}{ Male } & Control & 27 & $77 \pm 5$ & $23 \pm 5$ & $53 \pm 6$ \\
\hline & Select & 64 & $70 \pm 5$ & $24 \pm 5$ & $59 \pm 8$ \\
\hline \multirow{2}{*}{ Female } & Control & 24 & $75 \pm 5$ & $21 \pm 4$ & $47 \pm 5$ \\
\hline & Select & 55 & $73 \pm 6$ & $24 \pm 4$ & $52 \pm 6$ \\
\hline
\end{tabular}

Table 2. Number of lambs and means (SE) for age, initial and final weights, and ADG by performance test duration ${ }^{\mathrm{a}}$

\begin{tabular}{lrcccc}
\hline \hline Duration & No. & Age, d & Initial wt, kg & Final wt, kg & ADG, g \\
\hline $2 \cdot 4$ & 1,011 & $98 \pm 0.3$ & $29 \pm 0.2$ & $37 \pm 0.2$ & $263 \pm 3.6$ \\
$2 \cdot 6$ & 995 & $98 \pm 0.3$ & $29 \pm 0.2$ & $40 \pm 0.2$ & $261 \pm 2.7$ \\
$2 \cdot 8$ & 992 & $98 \pm 0.3$ & $29 \pm 0.2$ & $44 \pm 0.2$ & $277 \pm 2.5$ \\
$2 \cdot 10$ & 983 & $98 \pm 0.3$ & $29 \pm 0.2$ & $47 \pm 0.2$ & $250 \pm 2.1$ \\
$2 \cdot 12$ & 978 & $98 \pm 0.3$ & $29 \pm 0.2$ & $50 \pm 0.2$ & $245 \pm 2.0$ \\
$2 \cdot 14$ & 966 & $98 \pm 0.3$ & $29 \pm 0.2$ & $54 \pm 0.2$ & $249 \pm 1.7$ \\
$4 \cdot 4$ & 1,007 & $112 \pm 0.3$ & $33 \pm 0.2$ & $40 \pm 0.2$ & $256 \pm 3.1$ \\
$4 \cdot 6$ & 1,004 & $112 \pm 0.3$ & $33 \pm 0.2$ & $44 \pm 0.2$ & $253 \pm 2.5$ \\
$4 \cdot 8$ & 995 & $112 \pm 0.3$ & $33 \pm 0.2$ & $47 \pm 0.2$ & $245 \pm 2.1$ \\
$4 \cdot 10$ & 990 & $112 \pm 0.3$ & $33 \pm 0.2$ & $50 \pm 0.2$ & $240 \pm 1.8$ \\
$4 \cdot 12$ & 978 & $112 \pm 0.3$ & $33 \pm 0.2$ & $54 \pm 0.2$ & $245 \pm 1.7$ \\
$6 \cdot 4$ & 1,028 & $126 \pm 0.3$ & $37 \pm 0.2$ & $44 \pm 0.2$ & $253 \pm 3.0$ \\
$6 \cdot 6$ & 1,019 & $126 \pm 0.3$ & $37 \pm 0.2$ & $47 \pm 0.2$ & $243 \pm 2.5$ \\
$6 \cdot 8$ & 1,014 & $126 \pm 0.3$ & $37 \pm 0.2$ & $50 \pm 0.2$ & $237 \pm 2.0$ \\
$6 \cdot 10$ & 1,002 & $126 \pm 0.3$ & $37 \pm 0.2$ & $54 \pm 0.2$ & $245 \pm 1.8$ \\
\hline
\end{tabular}

${ }^{\text {a}}$ Duration coded by length (wk) of adjustment period and performance test, e.g., $2 \cdot 4$ indicates 2 wk of adjustment followed by $4 \mathrm{wk}$ of performance test. 
A repeated measures model using ADG data for each 2 -wk period of the performance test was investigated during preliminary statistical analyses. However, these analyses failed as estimates of the additive and permanent environmental variances converged to zero with all variability going to the residual variance. No reason for this anomaly was found, but typically analyses of ram performance tests do not consider repeated measures in evaluating ADG even when rams are weighed periodically. Therefore, the analyses with single measures may be more appropriate for analyses of current performance tests.

Knowledge of the genetic correlations among differing durations of a performance test will improve our understanding of the dynamics of genetic influences on measures of ADG. Two-trait analyses were performed only for selected durations of performance test. Models identical to those in the single-trait analyses were used.

\section{Results}

Means for lamb age, initial weight, and ADG for the parts of the performance test are reported in Table 2. Lambs were generally younger and lighter than most lambs placed on a performance test. Average daily gains ranged from 237 to $277 \mathrm{~g}$ and were similar to those reported for growing lambs (Shelton et al., 1954; Olson et al., 1976). Final weight increases with extended duration of performance test. Final weights are less than those reported for most performance tests because this test was intended to measure ADG during the typical feedlot growth stage rather than the growth of rams to a more mature state and older age. When this test was originally conducted, the average live lamb slaughter weights in the U.S. were within the range of 51 to 56 $\mathrm{kg}$ (USDA, ESS, 2002) which is in agreement with the growth stage during the performance for ADG.

Duration of performance test influenced estimates of variance components. Results from analyses in the single-trait model for ADG of the test period are reported in Table 3. Phenotypic variances were largest $\left(>50 \mathrm{~g}^{2}\right)$ when the performance test was only $4 \mathrm{wk}$ regardless of the adjustment period. Extending the duration of the performance test to $6 \mathrm{wk}$ reduced phenotypic variances to approximately $30 \mathrm{~g}^{2}$. Phenotypic variances continued to decrease with longer durations of performance test. The smallest phenotypic variance was from the 14-wk performance test period $\left(13 \mathrm{~g}^{2}\right)$. Decreases in phenotypic variance for $\mathrm{ADG}$ associated with extension of the feeding period have been reported in growing lambs (Olson et al., 1976) and calves (Swiger and Hazel, 1961).

Extending the adjustment period to 6 wk was associated with increasing the phenotypic variance of the performance test which may be related to the inverse relationship between age or weight and ADG as the animal matures during the test period.

The additive genetic and residual variances generally decreased as the duration of the performance test in- creased. The smallest additive and residual components of variance were for performance tests of $8 \mathrm{wk}$ or longer. Decreases in additive genetic variances did not result in comparable decreases in heritability estimates because proportional decreases in phenotypic variances were much greater. Heritability estimates were smallest for 4- or 6-wk performance tests irrespective of the adjustment period, and ranged from 0.10 to 0.20 , except for the combination of a 2 -wk adjustment period followed by a 6 -wk performance test $\left(h^{2}=0.29\right)$. Performance tests with a duration of $8 \mathrm{wk}$ or longer resulted in the largest heritability estimates that ranged from 0.24 to 0.38. Similarly, Koch et al. (1982) reported that heritability estimates for ADG in cattle increased with the duration of the performance test. For beef cattle, accuracy of measuring genetic effects increased by extending the feeding period to $168 \mathrm{~d}$ rather than limiting the feeding period to 56 or $112 \mathrm{~d}$ (Swiger et al., 1961). However, a shorter post-weaning performance test of 90 d was recommended by Swiger and Hazel (1961) when selecting for growth rate of bulls to $1 \mathrm{yr}$ of age.

Heritability estimates generally decreased when the adjustment period exceeded $2 \mathrm{wk}$, especially noticeable for the same durations of the performance test. However, when the duration of the performance test period was lengthened to 10 -wk preceded by an adjustment period of 4-wk, the heritability estimate increased to approximately 0.30 . Lengthening the adjustment period beyond a 2 -wk period had no evident advantage for estimating heritability of ADG. The heritability estimates for post-weaning ADG agree with earlier estimates of 0.34 (e.g., Harrington et al., 1962). Olson et al. (1976) also reported a higher range of heritability estimates for $\mathrm{ADG}$ from a combined half-sib analyses of seven different breeds that ranged from 0.31 to 0.46 for lengths of time on feed. Waldron et al. (1990) reported low and unreliable heritability estimates $\left(h^{2}=\right.$ 0.0023 ) and poor estimates of breeding value for $\mathrm{ADG}$ from a Suffolk performance test with too short of a duration (63-d test) to evaluate genetic differences.

Fractions of the phenotypic variance due to environmental (residual) effects were largest for 4- and 6-wk performance tests (ranging from 0.8 to 0.9 ), except when a 2 -wk adjustment period was followed by a 6 -wk performance test (0.7). For 8-wk or longer duration on test, the influence of environmental effects was relatively constant, ranging from 0.62 to 0.76. Animal performance for gain can be subject to several environmental factors including feed quality, weight and age on test, weather conditions, disease, management, pen effects, and so forth.

Results from the single-trait analyses clearly imply that variances for ADG can be influenced by the duration of the adjustment period and of the performance test. A short adjustment period of 2 to 4 wk with a 6 wk or longer performance test resulted in the highest heritability estimates and thus accounted for more of the total genetic variation between animals. For beef cattle, an adjustment period of $4 \mathrm{wk}$ was not sufficient 
Table 3. Estimates of variance components and fractions of total variance ${ }^{a}$ for ADG $\left(\mathrm{g}^{2}\right)( \pm \mathrm{SE})$ by performance test duration ${ }^{\mathrm{b}}$ from single-trait analyses

\begin{tabular}{|c|c|c|c|c|c|}
\hline Duration & $\sigma_{\mathrm{p}}^{2}$ & $\sigma_{\mathrm{a}}^{2}$ & $\sigma_{\mathrm{e}}^{2}$ & $\mathrm{~h}^{2}$ & $\mathrm{e}^{2}$ \\
\hline $2 \cdot 4$ & 54.8 & 11.0 & 43.8 & $0.20 \pm 0.06$ & $0.80 \pm 0.06$ \\
\hline $2 \cdot 6$ & 29.4 & 8.5 & 20.9 & $0.29 \pm 0.07$ & $0.71 \pm 0.07$ \\
\hline $2 \cdot 8$ & 22.1 & 7.2 & 14.9 & $0.33 \pm 0.07$ & $0.67 \pm 0.07$ \\
\hline $2 \cdot 10$ & 16.0 & 5.3 & 10.7 & $0.33 \pm 0.07$ & $0.67 \pm 0.07$ \\
\hline $2 \cdot 12$ & 14.5 & 5.5 & 8.9 & $0.38 \pm 0.07$ & $0.62 \pm 0.07$ \\
\hline $2 \cdot 14$ & 12.7 & 4.4 & 8.3 & $0.35 \pm 0.07$ & $0.65 \pm 0.07$ \\
\hline $4 \cdot 4$ & 51.2 & 8.3 & 42.9 & $0.16 \pm 0.06$ & $0.84 \pm 0.06$ \\
\hline $4 \cdot 6$ & 30.5 & 6.1 & 24.5 & $0.20 \pm 0.06$ & $0.80 \pm 0.06$ \\
\hline $4 \cdot 8$ & 20.0 & 4.9 & 15.1 & $0.24 \pm 0.07$ & $0.76 \pm 0.07$ \\
\hline $4 \cdot 10$ & 17.3 & 5.5 & 11.8 & $0.32 \pm 0.07$ & $0.68 \pm 0.07$ \\
\hline $4 \cdot 12$ & 15.1 & 4.4 & 10.7 & $0.29 \pm 0.07$ & $0.71 \pm 0.07$ \\
\hline $6 \cdot 4$ & 62.8 & 6.2 & 56.7 & $0.10 \pm 0.06$ & $0.90 \pm 0.05$ \\
\hline $6 \cdot 6$ & 32.2 & 5.3 & 26.9 & $0.16 \pm 0.06$ & $0.84 \pm 0.06$ \\
\hline $6 \cdot 8$ & 24.8 & 6.3 & 18.5 & $0.25 \pm 0.07$ & $0.75 \pm 0.07$ \\
\hline $6 \cdot 10$ & 19.6 & 4.8 & 14.8 & $0.24 \pm 0.07$ & $0.76 \pm 0.07$ \\
\hline
\end{tabular}

${ }^{\mathrm{a}} \sigma_{\mathrm{p}}^{2}=$ phenotypic variance; $\sigma_{\mathrm{a}}^{2}=$ genetic variance; $\sigma_{\mathrm{e}}^{2}=$ residual variance; $\mathrm{h}^{2}=$ heritability; $\mathrm{e}^{2}=$ fraction of phenotypic variance due to environmental effects.

${ }^{b}$ Duration coded by length (wk) of adjustment period and performance test, e.g., $2 \cdot 4$ indicates 2 wk of adjustment followed by $4 \mathrm{wk}$ of performance test.

to remove pre-test carry-over effects in bulls weaned under different environmental conditions (De Rose et al., 1988b). The animals in this study were of similar genetic and management background. A performance test for animals of differing backgrounds may require a longer adjustment period to remove pre-test carryover effects. Biases and significant reranking of sires due to pre-test carry-over effects in cattle were reduced when a two-trait animal model incorporated ADG to weaning and ADG during performance test (De Rose et al., 1988a).

Seven favorable lengths for performance test based on low phenotypic variances and high heritability estimates were identified with a 2 -wk adjustment period followed by 6 - to 14-wk performance tests or with a 4wk adjustment period followed by a 10 - to 12 -wk performance test. Heritability estimates for these combinations ranged from 0.29 to 0.38 , and phenotypic variances ranged from 13.7 to $22.1 \mathrm{~g}^{2}$, except the 6-wk performance test following a 2 -wk adjustment period had a larger phenotypic variance $\left(29.4 \mathrm{~g}^{2}\right)$.

Variance component estimates from the two-trait analyses among performance test durations were similar to those in the single-trait analyses with differences less than three digits at the second-decimal place. Therefore, only genetic and environmental correlations among performance tests of different durations are reported (Table 4).

Genetic correlations among performance tests of the seven favorable durations were large (from 0.88 to 1.00 ), as would be expected from large part-whole relationships. The large genetic correlations suggest that performance tests for the seven durations were genetically similar (Robertson, 1959). Therefore, selection based on performance in tests of any of the seven durations would have a positive effect on performance in all other periods of performance. The correlations also suggest that comparison of rams for EBV for ADG as measured in different performance tests may not be affected very much by differing durations of the adjustment and performance test periods, provided that performance in tests of different durations is as positively genetically correlated in this study. Another implication is that the duration of performance test may be shortened and still provide reliable estimates of genetic differences. Similarly, recommendations have been made to shorten the length of the performance testing period for American beef bulls (Brown et al., 1991) and Japanese Wagyu bulls (Sasaki et al., 1982) without affecting rank for genetic merit. In contrast, Olson et al. (1976) reported small genetic correlations for ADG between adjacent periods in post-weaning growth trials in ram lambs. They suggested that recording errors and variation in digestive tract fill resulted in small correlations. Therefore, they recommended that a growth period of at least 8 to $12 \mathrm{wk}$ is needed to estimate ADG performance.

Estimates of environmental correlations ranged from 0.31 to 1.00 . The larger environmental correlations were associated with durations of test closely similar in time, e.g., $2 \cdot 12$ and $4 \cdot 12$ with an estimate of environmental correlation of 1.00 . The smaller environmental correlations generally occurred for a short duration period compared with a long duration, e.g., $2 \cdot 6$ and $4 \cdot 10$ with estimates of environmental correlation of 0.33 , as is reasonable to expect.

Limitations to this study should be recognized. As previously mentioned, performance tests may vary with environmental factors (feed, management, facilities, age of lamb, etc.) that can influence variation in animal growth rates. In addition, not all factors typical of performance tests could be considered in this study. For example, lambs in this study were all from the same 
Table 4. Genetic and environmental correlations ${ }^{a}$ for ADG for performance tests of different duration ${ }^{\mathrm{b}}$ from two-trait analyses

\begin{tabular}{lccc}
\hline \hline Duration 1 & Duration 2 & $\mathrm{r}_{\mathrm{g}}$ & $\mathrm{r}_{\mathrm{e}}$ \\
\hline $2 \cdot 6$ & $2 \cdot 8$ & 1.00 & 0.62 \\
$2 \cdot 6$ & $2 \cdot 10$ & 0.98 & 0.56 \\
$2 \cdot 6$ & $2 \cdot 12$ & 0.91 & 0.52 \\
$2 \cdot 6$ & $2 \cdot 14$ & 0.92 & 0.46 \\
$2 \cdot 8$ & $2 \cdot 10$ & 0.99 & 0.73 \\
$2 \cdot 8$ & $2 \cdot 12$ & 0.95 & 0.63 \\
$2 \cdot 8$ & $2 \cdot 14$ & 0.94 & 0.55 \\
$2 \cdot 10$ & $2 \cdot 12$ & 0.95 & 0.80 \\
$2 \cdot 10$ & $2 \cdot 14$ & 0.93 & 0.70 \\
$2 \cdot 12$ & $2 \cdot 14$ & 0.97 & 0.82 \\
$4 \cdot 10$ & $2 \cdot 6$ & 0.98 & 0.33 \\
$4 \cdot 10$ & $2 \cdot 8$ & 1.00 & 0.53 \\
$4 \cdot 10$ & $2 \cdot 10$ & 1.00 & 0.95 \\
$4 \cdot 10$ & $2 \cdot 12$ & 0.96 & 0.66 \\
$4 \cdot 10$ & $2 \cdot 14$ & 0.96 & 0.66 \\
$4 \cdot 10$ & $4 \cdot 12$ & 0.94 & 0.77 \\
$4 \cdot 12$ & $2 \cdot 6$ & 0.88 & 0.31 \\
$4 \cdot 12$ & $2 \cdot 8$ & 0.92 & 0.44 \\
$4 \cdot 12$ & $2 \cdot 10$ & 0.93 & 0.64 \\
$4 \cdot 12$ & $2 \cdot 12$ & 1.00 & 1.00 \\
$4 \cdot 12$ & $2 \cdot 12$ & 0.96 & 0.72 \\
\hline
\end{tabular}

${ }^{\mathrm{a}} \mathrm{r}_{\mathrm{g}}=$ genetic correlation; $\mathrm{r}_{\mathrm{e}}=$ environmental correlation.

${ }^{\mathrm{b}}$ Duration coded by length (wk) of adjustment period and performance test, e.g., $2 \cdot 4$ indicates 2 wk of adjustment followed by $4 \mathrm{wk}$ of performance test.

flock and management system, whereas herd of origin has been shown to be the most important factor affecting all traits considered in a Canadian bull performance test (Liu and Makarechian, 1993) although, the effect of herd of origin on ADG decreased as the test period increased.

\section{Implications}

Accurately identifying genetic differences between animals for ADG requires a test period that can most accurately estimate genetic differences. This study implies that the largest amount of genetic variation in ADG can be accounted for when lambs are adjusted to the feed ration for 2 to $4 \mathrm{wk}$ and then performance tested for a 6 - to 14 -wk period. This study can not be used to provide a general recommendation for the length of the performance test for evaluating $\mathrm{ADG}$ for all environments and management practices. However, this study does show that duration of performance test can influence estimation of breeding values. Also, those conducting performance tests for ADG may consider the cost-savings of reducing a long-term performance test to a shorter term while still providing an accurate measure of genetic differences. This latter suggestion may not be practical when other traits of interest require longer durations to measure such as wool characteristics.

\section{Literature Cited}

Boldman, K. G., L. A. Kriese, L. D. Van Vleck, C. P. Van Tassell, and S. D. Kachman. 1995. A Manual for Use of MTDFREML. A set of programs to obtain estimates of variances and covariances. ARS, USDA Clay Center, NE.

Brown, A. H., Jr., J. J. Chewning, Z. B. Johnson, W. C. Loe, and C. J. Brown. 1991. Effects of 84-, 112- and 140-day postweaning feedlot performance tests for beef bulls. J. Anim. Sci. 69:451-461.

De Rose, E. P., J. W. Wilton, and L. R. Shaeffer. 1988a. Accounting for pretest environment and selection in estimating breeding values for station-tested beef bulls. J. Anim. Sci. 66:635-639.

De Rose, E. P., J. W. Wilton, and L. R. Shaeffer. 1988b. Estimation of variance components for traits measured on station-tested beef bulls. J. Anim. Sci. 66:626-634.

Dodenhoff, J., L. D. Van Vleck, S. D. Kachman, and R. M. Koch. 1998. Parameter estimates for direct, maternal and grandmaternal genetic effects for birth weight and weaning weight in Hereford cattle. J. Anim. Sci. 76:2521-2527.

Dodson, M. V., S. L. Davis, D. L. Ohlson, and S. K. Ercanbrack. 1983. Temporal patterns of growth hormone, prolactin and thyrotropin secretion in Targhee rams selected for rate and efficiency for gain. J. Anim. Sci. 57:338-342.

Graser, H.-U., S. P. Smith, and B. Tier. 1987. A derivative-free approach for estimating variance components in animal models by restricted maximum likelihood. J. Anim. Sci. 64:1362-1370.

Harrington, R. B., D. G. Brothers, and J. V. Whiteman. 1962. Heritability of gain of lambs measured at different times and by different methods. J. Anim. Sci. 21:78-81.

Knapp, D., R. W. Phillips, W. H. Black, and R. T. Clark. 1942. Length of feeding period and number of animals required to measure economy of gain in progeny tests of beef bulls. J. Anim. Sci. $1: 285-292$.

Koch, R. M., L. V. Cundiff, and K. E. Gregory. 1982. Influence of postweaning gain interval on estimates of heritability and genetic correlations. J. Anim. Sci. 55:1310-1318.

Liu, M. F., and M. Makarechian. 1993. Factors influencing growth performance of beef bulls in a test station. J. Anim. Sci. 71:1123-1127.

NRC. 1985. Nutrient Requirements of Sheep. 6th ed. National Academy Press, Washington, DC.

Olson, L. W., G. E. Dickerson, and H. A. Glimp. 1976. Selection criteria for intensive market lamb production: growth traits. J. Anim. Sci. 43:78-89. 
Robertson, A. 1959. The sampling variance of genetic correlation coefficient. Biometrics 15:469-485.

Sasaki, Y., H. Iwaisaki, T. Masuno, and S. Asoh. 1982. Interaction of sire $\times$ length of testing period and estimation of genetic parameters for performance testing traits of Japanese black bulls. J. Anim. Sci. 55:771-779.

Shelton, M. 1979. Estimation of genetic change in a performance testing program for sheep. J. Anim. Sci. 48:26-31.

Shelton, M., J. C. Miller, W. T. Magee, and W. T. Hardy. 1954. A summary of four years work in ram progeny and performance testing. J. Anim. Sci. 13:215-228.

Swiger, L. A., and L. N. Hazel. 1961. Optimum length of feeding period in selecting for gain of beef cattle. J. Anim. Sci. 20:189-194.
Swiger, L. A., R. M. Koch, K. E. Gregory, and V. H. Arthaud. 1961. Effect of length of the feeding period on accuracy of selection for gain and feed consumption in beef cattle. J. Anim. Sci. 20:802-808.

USDA, ESS, 2002. Historical reports for the US livestock sheep market, 1972-1997. Available at: http://usda.mannlib.cornell.edu/ data-sets/livestock/94145. Accessed Feb. 19, 2002.

Waldron, D. F., D. L. Thomas, J. M. Stookey, T. G. Nash, F. K. McKeith, and R. L. Fernando. 1990. Central ram tests in the midwestern United States: III. Relationship between sire's central test performance and progeny performance. J. Anim. Sci. 68:45-53. 